\title{
POSITIVE PERSONALITY TRAIT IN KAHLIL GIBRAN'S THE BROKEN WINGS
}

\author{
Dea Jesikha, Purwarno, M. Manugeren \\ Master's Program, Fakultas Sastra, \\ Universitas Islam Sumatera Utara, Medan, Indonesia \\ Corresponding author: deajesikha@gmail.com
}

\begin{abstract}
The objectives of the research are to identify positive personality traits in the poetical novella of The Broken Wings and to expose some actions, thoughts and feelings of the major characters that could be categorized into positive personality traits. Some related theories on personality traits are applied in this research, one of which, is the one proposed by Lauther (2012) stating that personality traits appear in the forms of action, attitude and behavior some may be positive such as: love, friendship, respect, honesty, responsibility, adaptability, compatibility, resolution, compassion, patience, courage and loyalty; while some others negative such attitude as laziness, shyness, arrogance, closeness , dishonesty, cruelty, and intolerance. The research is conducted by means of qualitative descriptive method proposed by Kothari (2004) having a goal of a comprehensive summarization, in everyday terms, of specific events experienced by individuals or groups of individuals. The research results show that there are four significant positive personality traits found in the whole course of the story: Love, Friendship, Resolution and Respect and these traits are all experienced by the major characters.
\end{abstract}

Key words: love, friendship, resolution and respect

\section{Introduction}

Kahlil Gibran's unique poetic expression, characterized by beauty and spirituality, became known as "Gibranism." His language touches the inner souls of readers and his parables teach them spiritual lessons. His early short stories, prose poems, and later collections of aphorisms made him widely acclaimed as the greatest of Arab Romantics.

Many critics think that Gibran's poetic genius predominantly lies in the use of metaphor. Gibran indeed creates beautiful images that are charged with emotions and that expand the reader's vision and imagination. He addressed various subjects about life and humanity like love, beauty, truth, justice, good and evil. (Daodi, 2009)

As Gibran's interest shifted to mysticism and primitivism, his writings returned again and again to the beauty and purity of nature. He romanticized nature and found in it an inspirational power for his poetry. He identifies the divine essence with the natural world, termed Pantheism which he had absorbed from his readings under Fred Holland 
Day's tutelage. Gibran's writings establish a mystical union with nature, a relationship of love and harmony. The natural beauty of Gibran's home village Bisharri was a strong source of inspiration and nurture to his imagination. His poetry is nostalgic of the magnificent scenery of his childhood. It portrays Gibran rejoicing in peace and freedom among the immortal cedars of Lebanon, the famous holy valley of Qadisha, and the mountains of Sannin and Famm al-Mizab. (Bushrui and Jenkins, 2008).

The Broken Wings was first published in 1912, (Al-Ajnihah al Mutakassirah), one of Kahlil Gibran's early experimental works through which he sought to reform the Arabic literature and culture. In a manner unknown in traditional Arabic writing, it is free from rhetorical flourishes but more importantly, it debates the issue of the oppressed Arab woman in the Middle Eastern society of the late nineteenth and early twentieth century.

It is Gibran's longest sustained narrative, written in the tradition of "Romeo and Juliet" and based on oriental settings and images. Inspired by his own first love and bitter experience in his home village Bsharri, The Broken Wings gives the taste of the bittersweet, of the beauty and pain of young love. It is an alive and profound story characterized by beautiful prose and evocative imagery, a tale of passion doomed by the restrictions of society and the power and greed of the clergy.

From another romantic perspective, Gibran once again describes the beautiful nature in North Lebanon which fired his imagination and stirred his homesickness up to his death. In the "Forward" we see him rejoicing in spiritual exaltation from remembering those valleys full of magic and dignity, and "those mountains covered with glory and greatness trying to reach the sky" (Gibran, 2007:18)

Young Kahlil is introduced to Faris Karama, a wealthy widower, and immediately falls in love with Selma, Karama's only child. Selma is equally attracted to Kahlil. But a powerful priest, who is after the family's fortune, puts pressure on Faris Karama and demands Selma's hand for his nephew Mansoor Bey. Despite Selma's protests, her father accepts the match and sends his daughter to a loveless life. With Fares' death, Mansoor Bey takes over Selma's inheritance and begins to waste it in gambling and other thoughtless spending. Meanwhile, Selma resumes her chaste relationship with Kahlil. But when Mansoor Bey becomes suspicious, he demands that Selma gives him an heir. She chooses to confine herself to her new life and thinks of her future infant as a guide out of the unhappiness that imprisons her. Selma's baby dies minutes after birth and she follows him because of weak health. Kahlil finds himself alone in agony by Selma's tomb.

Gibran's narrator delicately paints his feelings when describing the blossoming of his love. He talks about Selma's unparalleled beauty and virtue, her sweetness and nobility of spirit. She lives inside him as a "supreme thought, a beautiful dream, an overpowering emotion". (Gibran, 2007: 52)

He believes in the transcendental power of Romantic love and in its ascendancy over tradition. For him, true love is a supreme way of achieving self-realization and is the 
noblest of human attainment. It becomes a spiritual accord that brings him heavenly inspiration, for through Selma's eyes he sees the angels of Heaven looking at him. (Gibran, 2007: 20)

The story, however, illustrates Gibran's attempts at approaching universal truths. He reflects on the meaning of the human existence and portrays himself as a champion of women and of the values of human freedom and dignity. Gibran's works speak of women having a ring of modernity about them as they deal with issues that are still burning.

The story is truly sad and tragic, and paints endlessly a pure love between two. Gibran, with all the metaphors and figures of speech in the book, shows the reader what he thinks and how he feels about a genuine love between a man and a woman, and the union of two souls, regardless of whether or not they end up being together.

The Broken Wings is a piece of art, where he shows the readers his language skills, and knowledge of history, beliefs, cultures and psychology. Regarding this, the focus of this study is concerned with positive personality traits of the major characters with four points of discussion Love, Friendship, Resolution, and Respect.

\section{Literature Review \\ Personality Trait}

The study of personality and what shapes and influences each person is fascinating as people study this field have varying opinions on personality. However, they do build off one another and theorists tend to refine the work of their predecessors, which is common in all scientific pursuits. What is most important to understand is that everyone has different personality traits. People each have certain traits that dominate their personality with a myriad of traits that can arise in different situations and their traits can change over time and can be shaped by their experiences.

Everyday conceptions of personality traits make two key assumptions. First, traits are stable over time. Most people would accept that an individual's behavior naturally varies somewhat from occasion to occasion but would maintain also that there is a core of consistency which defines the individual's 'true nature': the unchangeable spots of the leopard. In other words, there are differences between individuals that are apparent across a variety of situations. We might expect a student we have noted as a 'worrier' to be unusually disturbed and worried in several different contexts such as examinations, social occasions and group discussions. Stability distinguishes traits from more transient properties of the person, such as temporary mood states. Second, it is generally believed that traits directly influence behavior. If a person spontaneously breaks into cheerful song, we might 'explain' the behavior by saying that he or she has a happy disposition. Such lay explanations are, of course, on shaky ground because of their circularity. Aristotle suggested a more subtle, reciprocal causal hypothesis: that it is through actions that dispositions develop, which in turn influence actions. (Matthew, et.al, 2003) 
One of the major tasks for a scientific psychology of traits is to distinguish internal properties of the person from overt behaviors, and to investigate the causal relationships between them. To avoid circularity, it is essential to seek to identify the underlying physiological, psychological and social bases of traits, which are the true causal influences on behavior. (Matthew, et.al, 2003)

There are many different personality types, according to the Lauther Type Indicator, but it is sometimes difficult to classify a person as a single type. There are many different personality traits you can possess and they may not all fit into one category. Personality traits appear in the forms of action, attitude and behavior. Some personality traits are positive such as: love, friendship, respect, honesty, responsibility, adaptability, compatibility, resolution, compassion, patience, courage and loyalty; while the negative ones are traced through such attitude as laziness, shyness, arrogance, closeness, dishonesty, cruelty, and intolerance. Other attitudes not mentioned in the list might be categorized into one as the head trait. (Lauther, 2012: 143)

Most theorists and psychologists agree that people can be described based on their personality traits and theorists continue to debate the number of basic traits that make up human personality. While trait theory has an objectivity that some personality theories lack, such as Freud's psychoanalytic theory, it also has weaknesses. Some of the most common criticisms of trait theory center on the fact that traits are often poor predictors of behavior. While an individual may score high on assessments of a specific trait, he may not always behave that way in every situation. Another problem is those trait theories do not address how or why individual differences in personality develop or emerge. (Allport, 2015: 13)

\section{Research Method}

In this study, the researcher uses qualitative descriptive method in collecting and analyzing the data. According to Kothari (2004), descriptive research includes surveys and fact-finding inquiries of different kinds. He also believes that the main characteristics of descriptive method are that the researcher has no control over the variables; the researcher can only report what has happened or what is happening. The goal of qualitative descriptive studies is a comprehensive summarization, in everyday terms, of specific events experienced by individuals or groups of individuals.

The primary data are taken from the poetical work of The Broken Wings while the data sources are all the quotations delivered by the major characters. Data collection procedures are focused on discovering the nature of specific events belonging to the study, and in this case all events manifested in the forms of words picturing love, friendship, resolution and respect.

\section{Discussion}

Love

Many people have lost the true meaning of love. Love is a very important part of one's life, and if there is uncertainty, it should not be pursued. The true meaning of love is to be in a complete and total bond with each other and care for each other when others 
flee. While many people try to achieve love in other ways, such as seeking financial support or having someone to support them in ways that they should do on their own, is not the true meaning of love. The ideas stated in the last sentence would help relationships but would blur the overall meaning of love.

Love can be defined as a strong bond between people. There are many types of love: brotherly love, motherly love, love for pets, love for activities or places, and everyone's favorite- romantic love. The purpose of this article is to focus solely on romantic love between two people. Romantic love will be defined as a profoundly tender, passionate for another, including sexual desire and passion. But the sexual part takes the emotional, psychological and spiritual love to another level; the physiological level. Sex alone though is not love. This should be obvious. It can be the thing that makes someone smile in the morning or the thing that makes him cry at night. A deep, true love can be something that is bigger than obsession, a deeper connection with another human being in which people can share their whole selves with the other person; their likes and dislikes, passions, fears, memories, dreams, and spend quality time with each other. (Cloninger, 2010: 87)

Even though love is a mixture of chemicals in the brain it is also a combination of emotions exhibited by the human race. It is the feelings of joy, support, and Strength given through companionship. Love is supposedly the great connector between different people around the globe. Love has driven mankind and its actions for centuries and will do so for centuries to come. Love for others and for heritage and home, provides a stable ground for a diverse community such as our world. But those lacking these basic emotions in their lives can cause disturbances in peoples lives. Even those with a love for their heritage or country may cause cracks in this "stable ground" if they cannot accept other peoples love for their own heritage or beliefs. True love for the romanticist is the ultimate goal, the purest form of love.

This kind of positive personality trait is dominant in the novel because this novel belongs to the poetical romantic novel. This novel tells a story about Gibran's love experience when he is eighteen years old. That is why this novel is full of love stuff. Unfortunately, the story is not finished with a happy ending; yet the existence of love is highly valued.

Gibran expresses his love towards his lover, Selma, in an exaggerated way, eulogizing her beauty and her kindness towards him.

I was eighteen years of age when love opened my eyes with its magic rays and touched my spirit for the first time with its fiery fingers, and Selma Karamy was the first woman who awakened my spirit with her beauty and led me into the garden of high affection, where days pass like dreams and nights like weddings. (Gibran, 2007: I-2-3)

Here it is clear that Gibran speaks highly of Selma and expresses his love excessively towards Selma. Selma becomes the first woman who could awaken his spirit to face life and challenges all the hardship of life. He will be highly-spirited to do anything for the sake of his love. 
The utterance of Gibran above is only a part of Gibran's thought spilled in the foreword of the novel. The earlier of the page is the story of Gibran"s appreciation towards Selma and the story of Gibran"s love to Selma. Even all the content of the novel actually tells about the intimate relationship between Gibran and Selma. It is continued to the end of the novel. Another scene that depicts the intimate relationship between Gibran and Selma is depicted below.

Thus ended the hour of my first meeting with Selma, and thus the will of Heaven freed me from the bondage of youth and solitude and let me walk in the procession of love. (Gibran, 2007: II-9)

Here it is seen how Gibran feels as if he were flying to end of the sky as he is fully satisfied in expressing his love towards Selma. Having met Selma for on hour, Gibran feels that all his difficulties in life are relieved and with a high spirit he could walk gallantly towards his future.

Another point of love shown by Gibran towards Selma is illustrated below:

The sorrowful spirit finds rest when united with a similar one. They join affectionately, as a stranger is cheered when he sees another stranger in a strange land. Hearts that are united through the medium of sorrow will not be separated by the glory of happiness. Love that is cleansed by tears will remain externally pure and beautiful. (Gibran, 2007: IV -11)

Gibran states that a sad heart could be soothed only when joined with another heart. He knows for sure that Selma is not happy unless she is with him. He gives an analogy of two strangers having the same problem and when they met, they will comfort each other releasing the burden of mind and feeling. Two hearts with the same problems will easily be united and the true love is love that is always watered by tears and such a love could not be easily damaged either by time or condition.

\section{Friendship}

Friends play an important role in a person's life. They encourage when one is sad, they entertain when one is lonesome, and they listen when one has problems. There are varieties of friends: co-workers, social workers, schoolmates, and much more. Each type of friends is helpful in one way or the other. A true friend is one who never deserts you, and always remain faithful towards you. He is a close companion who is honest and sincere towards your feelings. He sticks to all the time whether it is the time of happiness or sorrow. He is an inseparable companion even in the midst of great distress, in poverty and in other times of need.

Unlike false friends, true friends accept all your weaknesses, appreciate your efforts, and never judges you on the basis for your achievements or failures. False friends are fair weather companions. They always knock at your door when you are rich or affluent and have enough and to spare. They are with our intimates of good fortune marked by plentifulness and prosperity and desert in rough weather. 
The things which form the basis of true friendship are, mutual trust and togetherness so that you forget your mutual otherness and come closer together, love from the deep hearts core, understanding and appreciation of each other's views., fellow-feeling, sympathy, broad-mindedness, service and sacrifice. It is always difficult to cultivate these virtues but for keeping up friendship in the true sense of the term, it is desirable. (Feist, 2012: 45)

Gibran is a lucky boy because he has a good father. His father's kindness is also reflected in him.

You are the son of a very dear friend of mine, and I am happy to see that friend in your person. (Gibran, 2007: I-31)

Farris is a friend of Gibran's father and Gibran meets Farris in Lebanon. Gibran is a very respectful young man who respect the elders, and he also respects everyone he knows. This makes Farris fall in love with Gibran and love him very much. Farris who is much older than Gibran could befriend Gibran simply because Gibran has got a significant positive personality trait in the form of love.

Fate has brought back to me a dear old friend of mine in the person of his son. (Gibran, 2007: I-8)

Their friendship is very harmonious and there are no words or deeds from any one of them that can ruin their relationship. And this friendship continues until Farris dies. Farris's departure is a very heavy blow to Gibran. He must be willing to let go of his friend with a very heavy heart until he finally suffers greatly.

\section{Resolution}

Some people believe that talent and a winning attitude are all you need in order to succeed in your endeavors, but a winning attitude means having resolution, which many people lack. Resolution is an important factor in the overall success or failure of a person's efforts. Unfortunately, resolution is not something that comes easy to the majority of people. To be truly determined, a person must first be passionate about what they are doing. Passion, however, is only the first step towards resolution. One must have a clear goal in mind, and be willing to do anything to achieve said goal.

Resolution is one of Nature's mysterious mechanisms, which is not confined to humans only. Animals also show great resolution to protect themselves from enemies and threats and survive against odds. There is no doubt that resolution is embedded in advanced life forms, which keeps them life-oriented and survive in difficult and varied environments. (Engler, 2013: 65 - 8)

In human beings it appears that resolution is deeply ingrained as part of our survival instinct and self-expression. However, it may not equally manifest in all due to various influences. We can see that people vary in their resolution to pursue their goals and desires. Some people easily give up, and some go to the end. Some people do not try at all, while some never give up until they finish what they start. 
Such differences are mainly due to the differences in their thinking and attitude and due to various intrinsic and extrinsic factors, such as beliefs, social and cultural influences, fear, self-esteem, the strength of the desires, the rewards or the pay off involved. It suggests that while resolution may a part of your natural instinct to survive, it may also be learned and sustained by conscious effort and changing your thinking and attitude.

Here it is seen how Gibran and Selma make a resolution owing to Selma's marriage. They know that it is quite hard for them to meet each other anymore as often as they like as Selma has been tied to a marriage. They make a resolution of a farewell.

We stood up and bade each other farewell, but love and despair stood between us like two ghosts, one stretching his wings with his fingers over our throats, one weeping and the other laughing hideously. (Gibran, 2007: $\mathrm{VI}-27)$

With tears flowing down their cheeks, they have to say goodbye to each other; a resolution that is not easy to be conducted especially between two lovers; yet here lies the positive trait as Selma does not belong to Gibran, but her husband and husband has fully right upon her. They basically do not want to be separated but fate speaks in a different way. They have to be separated by nature in the form of the tradition. A married woman is not allowed to meet another man, especially for matters of love. In short it is strictly stated that a married woman is strictly prohibited to have a love affair with another man; whatever the reason is.

But unfortunately, the power of love is enormous and the two lovers cannot withstand that power. They have agreed not to meet each other because of the dividing fortress of Selma's marriage. But they suffer greatly and eventually they again make a resolution that they would meet only once a month.

In that unknown temple, I met Selma once every month and spent the hours with her...We feared not the observer's eyes; neither did our consciences bother us ... (Gibran, 2007: IV - 37-38)

From the point of tradition and community norms they are wrong; but the love they have is above all human rules. They watch and care for each other and they do not want any of them to suffer just because of a rule. Eventually they give up with the power of their love. The second resolution they make has two interpretations. On the one hand, they have violated the rules but on the other hand this second resolution is a positive trait reflection that is responsibility and concern with each other. Responsibility for taking care of others basically has no connection with the existence of marriage because in a larger scale people should take care one another to sustain harmony.

\section{Respect}

Most people go through life and always hear about the word respect, but they do not know what it means. Respect is the esteem for or a sense of the worth or excellence of a person. There are things in life you need to hold in respect. Respect for yourself, respect for others, and respect for property. Respect is taught to people everywhere 
and it is even taught to them in their religions. Respect is the very aspect that keeps everything in your life.

A person should not only respect him self, but also other people. A person should give positive remarks to their friends. They should not put them down, by saying negative things about them. If the person respects his friend, then they think highly of them, and won't put them down. Also to show respect to people, one should listen to what others have to say. Lots of times when people speak to others, other people will talk to someone else, or just tune the speaker out. This does not show respect to the speaker. They should be quite and listen to the person speaking. Respecting others is very important if you want to be respected.

True respect is not earned of injuring oneself or breaking the law. The respect earned by that is not true and lasting, because it must be reaffirmed. It is so important for some to be respected that they would to that and more. However, the way to earn respect is to be respectful. Make it an attitude, not a thing given to a person after they have proven themselves. This way, it can not be demolished by anything. (Hogan and Smither, 2008: 134)

Selma is a very good girl. She is also clever and beautiful; and his ingenuity and beauty add to his obedience to his father. She is unable to say no to his father even though what his father says might not fit her heart.

His daughter obeys him in spite of her pride and intelligence, and this is the secret which lurks in the life of father and daughter. (Gibran, 2007: III-6)

Herein lies the harmony of a relationship between a daughter and her father. Her father wants her to marry Mansour while Selma will never be able to love Mansour. For Selma there is only a man in her heart, Gibran; but she does not have the heart to hurt her father and eventually she is willing to sacrifice her interest for the sake of the happiness of her father and she accepts her father's offer to marry Mansour.

Selma has proved herself to be very respectful of her parents. For her, the happiness of her father is her happiness too and hurting her father's heart is the reflection of an ungrateful child.

\section{Conclusions}

This is a plain, cool, calm, quiet, gentle, tendering, smooth and refreshing love story with a sad end. One dies at the end of the story, other also dies but lives and delivers the meaning to World. This world is too small. But still, it takes years to find out your true love. As a matter of fact, this life is too small but this book teaches you how to make each moment remarkable and memorable. This book tells you how to express yourself without uttering a word and how to listen to the silence. It tells you what the word does "Beloved" means and the meanings of Happiness and Sorrow. It tells how easy it is to understand the true Love and how difficult sometimes it becomes to hold it. 
Proceedings of the $1^{\text {st }}$ Annual International Conference on Language and Literature, 18-19 April 2018, Fakultas Sastra, UISU, Medan, Indonesia.

The Broken Wings gives the taste of the bittersweet, of the beauty and pain of young love. It is an alive and profound story characterized by beautiful prose and evocative imagery filled with precious moral values in the forms of positive personality traits. Tied to this, the research results show that there are four positive personality traits which are significant to be discussed: Love, Friendship, Resolution and Respect.

Gibran believes in the transcendental power of Romantic love and in its ascendancy over tradition. For him, true love is a supreme way of achieving self-realization and is the noblest of human attainment. It becomes a spiritual accord that brings him heavenly inspiration, for through Selma's eyes he sees the angels of Heaven looking at him (Gibran, 2007: I-20)

Selma, however, tells her beloved that the true nature of a woman's soul is a mixture of love and sorrow, affection and sacrifice. Her understanding of the situation is deeper and more complicated. Unable to overcome the values of her society, she chooses commitment to her father and unloving husband over running away to Kahlil's love, and so she sacrifices true love for social customs.

\section{References}

Allport, GW. (2014). Personality: A Psychological Interpretation. New York: Holt, Rinehart, \& Winston.

Bushrui, S. B., and Jenkins, Joe. (2008). Kahlil Gibran Man and Poet, A New Biography. Oxford: Oneworld Publications.

Cloninger, S.C. (2010). Theories of Personality: Understanding Persons. $8^{\text {th }}$ Ed. Boston: Pearson.

Daoudi, MS. (2009). The meaning of Khalil Gibran. Secaucus: Citadel Press.

Engler, B. (2013). Resolution in Personality Traits. Belmont: Wadsworth Publishing.

Feist, J. (2012). Theories of Personality: How to Maintain Friendship. Chicago: Bliar \& Bros.

Gibran, Kahlil, (2007). The Broken Wings. New York: Pearson \& Dodo

Hogan, R., \& Smither, R. (2008). Personality Theories and Applications. (2nd ed.). Tulsa, OK: Hogan Press.

Khotari, C. R. (2004). Research Metholodogy: Methods and Techniques. New Delhi: New Age International $(P)$ Ltd., Publishers.

Lauther, Howard. (2012). Creating Characters: A Writer's Reference to the Personality Traits That Bring Fictional People to Life. New York: McFarland.

Matthews, Gerald, et.al. (2003). Personality Traits. Edinburgh: University of Edinburgh. 